\title{
皮 \\ PSICODINÂMICA DO RECONHECIMENTO NO TRABALHO DE INFORMÁTICA DE TERCEIRIZADOS E CONCURSADOS DA CÂMARA DOS DEPUTADOS
}

\section{THE PSYCHODYNAMIC RECOGNITION AT WORK COMPUTER OF OVERCHARGING AND PERMANET EMPLOYEES IN THE HOUSE OF REPRESENTATIVE}

\begin{abstract}
Márcio Martins*
Resumo: A pesquisa analisou a psicodinâmica do reconhecimento no trabalho de informática da Câmara dos Deputados investigando a organização do trabalho, as contradições entre o trabalho prescrito e o trabalho real e as vivências de prazer e sofrimento dos concursados e terceirizados. O método utilizado foi da psicodinâmica do trabalho com apoio da análise de discurso. Os dados coletados foram classificados como: organização do trabalho; vivências de prazer e sofrimento; e reconhecimento. Após a investigação os resultados comprovaram a precarização e fragilidade sócio-econômica dos terceirizados, apesar da visibilidade e reconhecimento de suas tarefas e, por parte dos concursados, sobrecarga e características de narcisismo.
\end{abstract}

Palavras-chaves: Psicodinâmica do reconhecimento; Terceirização; Informática; Reconhecimento no trabalho; Câmara dos Deputados.

\begin{abstract}
The research analyzed the psychodynamics of work in computer recognition of the Chamber of Deputies investigating the organization of work, the contradictions between prescribed work and real work and the experiences of pleasure and suffering of outsourced and permanent employees. The method used was the psychodynamics of work to support the analysis of speech. The data collected were classified as: organization of work; experiences of pleasure and pain; and recognition. After the investigation the results proved precarious and socio-economic fragility of outsourced, despite the visibility and recognition of their tasks, and by the permanent employees, overload and features of narcissism.
\end{abstract}

\footnotetext{
*Mestre em Psicologia Social do Trabalho e das Organizações (UnB), especialista em Educação (UCB), especialista em Gestão de Pessoas (UFMG) e graduado em Processamento de Dados e Informática. Atualmente faz parte do GT-Qualidade de Vida no Trabalho e coordena a área de cursos a distância do Cefor/Câmara dos Deputados (marcio.martins@ camara.leg.br).
} 
Keywords: Psychodynamic recognition; Outsourcing; Information technology; Recognition at work; Chamber of Deputies.

\section{Introdução}

Este artigo relata pesquisa sobre a psicodinâmica do reconhecimento no trabalho de profissionais de informática na Câmara dos Deputados investigando juntamente as vivências de prazer e sofrimento na organização. A relevância da pesquisa consiste na análise da dinâmica do reconhecimento, de forma comparativa, de duas categorias próximas geograficamente, mas distantes socialmente.

Verificou-se a confrontação de duas realidades opostas no serviço público: os concursados, que prestam serviços de forma regular e estável, com ingresso nos órgãos públicos via concurso; e os terceirizados, que prestam serviços por meio de um contrato frágil e temporário.

A terceirização é uma forma de contratação polêmica, do ponto de vista ético e legal. É um trabalho sem vínculo institucional, sem garantia de continuidade e menos benefícios. Já os concursados têm um vínculo formal com a instituição e estabilidade garantida por lei, o que na instituição garante status, além de salários bem superiores ao dos terceirizados. A hierarquia desproporcional em relação aos terceirizados implica em relações socioprofissionais desgastadas. Para Carvalho (2010), a terceirização tem se constituído em uma fonte de problemas trabalhistas, uma vez que o direito do trabalho não está suficientemente instrumentalizado para lidar com esse fenômeno. Apesar de decisões jurídicas em favor da legalidade desta prática, ou seja, do capital, Carvalho (2010) ressalta que o termo "terceirização" é uma criação brasileira para indicar que se transfere para "um outro", "um terceiro", uma atividade (periférica) que vinha sendo feita pela própria empresa. O autor (2010, p.16) afirma que a terceirização é a "erosão dos direitos dos trabalhadores".

Antunes (1995) e Dau et al. (2009), afirmam, em obras distintas, que o problema da terceirização não é a legalidade, mas a ética, pois no âmbito federal, o marco legal disciplinador da transferência de serviços para a iniciativa privada foi regulamentado pelo Decreto-Lei $\mathrm{n}^{\circ}$ 200/1967. A terceirização ficou permitida a não ser para as chamada "atividades exclusivas de Estado" e aquilo que não fosse "atividade fim" como, por exemplo, serviços de vigilância, conservação e limpeza e outros denominados "serviços de natureza auxiliar ligados à atividademeio". (DAU; RODRIGUES; CONCEIÇÃO, 2009, p.113-114).

Enquanto a terceirização é defendida por alguns administradores como uma modalidade de contrato eficaz, é vista por alguns estudiosos como uma contratação baseada na relação trabalho-capital, mas mostrando uma face perversa, isso em razão da luta pela empregabilidade alicerçada na exploração. Para manter a empregabilidade, o trabalhador, que é responsabilizado por sua situação, entra no jogo do individualismo, da rivalidade e da competição. O trabalhador 
se submete a qualquer condição para garantir seu lugar, pois a questão fundamental é sua subsistência e inclusão social.

Quem contrata não está alheio a essa realidade e tira proveito dessa situação, criando regras e lógicas que não dão chances para questionamentos. É, sem dúvida, uma forma de precarização e assujeitamento no trabalho. Por óbvio que os constrangimentos no trabalho não se resumem, apenas, a isso, a dominação e a invisibilidade que essa modalidade de contrato traz são notórias. Tudo isso passa pelo olhar de uma sociedade acostumada a banalizar a situação do outro.

Essas ideias têm fundamento nos estudos que acreditam que as condições de trabalho estão cada vez mais reféns da lógica da acumulação flexível de capital. Para Dejours (1999b), os trabalhadores estão em situação de desamparo legal e social nas relações de trabalho. De fato, não são remunerados devidamente pelo que fazem e convivem diariamente com ameaças, por causa do fantasma do desemprego (ANTUNES, 1995).

Segundo Gaulejac (2007), a sociedade atual é marcada por um desenvolvimento paradoxal, na qual a riqueza e a pobreza aumentam, assim como o conhecimento e a ignorância, a proteção e a insegurança. Além disso, há uma falta de sentido generalizada nas tarefas realizadas pelas pessoas, somada a uma condução perversa no processo de trabalho, assinalado pela competitividade que aceita qualquer tipo de regra e ética. Instalou-se a "luta pelos lugares" (GAULEJAC, 2007).

Pesquisas em Psicodinâmica do Trabalho, realizadas nos últimos cinco anos, demonstraram uma evolução na análise crítica das relações de trabalho que impactam na saúde psíquica do sujeito em situações no trabalho. Há vários estudos entre eles: Prazer-sofrimento e estratégias defensivas no trabalho de líderes de uma empresa do pólo industrial de Manaus (FONSECA e MORAES, 2012); análise psicodinâmica do trabalho no Tribunal de Justiça do Amazonas: uma aplicação da clínica do trabalho e da ação (GARCIA, 2011); a psicodinâmica do trabalho de profissionais de odontologia do centro ambulatorial de um hospital universitário (FERREIRA, 2013); psicodinâmica da relação gestor-equipe: análise do prazer-sofrimento no trabalho em uma organização pública (AGUIAR, 2013).

Nesta pesquisa, busca-se investigar os trabalhadores que atuam na área de informática, analisando o domínio e a captura da subjetividade desses no âmbito do serviço público, percorrendo a mesma linha de outros estudos, como o de Mansano e Malacrida (2011) intitulado "A relação homem-computador: um estudo sobre o sofrimento psíquico entre analistas de sistemas". Os resultados da pesquisa supramencionada mostraram que a carga psíquica acumulada por estes trabalhadores (no processo de adoecimento e prazer no contexto de trabalho) aparece diante da complexidade das tarefas a serem realizadas e das diferentes solicitações de resolução de problemas que exigem processos cognitivos complexos. O artigo abordou um sofrimento velado na luta para desligar, relaxar e se desconectar da máquina 
enquanto há uma busca incessante por soluções em meio à sobrecarga. O sofrimento manifestado entre analistas de sistemas está relacionado à hipótese de que esses profissionais, na qualidade de sujeitos divididos entre a obediência e resistência às demandas organizacionais, acolhem as "proibições" em relação à manifestação do sofrimento, reproduzindo, assim, a atual cultura do individualismo na gestão do trabalho.

A história da informática no setor público brasileiro se confunde com a história da automação dos escritórios. Hoje, observa-se uma dependência institucionalizada em relação às ferramentas tecnológicas apoiadas em sistemas computacionais e, consequentemente, uma sobrecarga às pessoas que desenvolvem e mantêm tais ferramentas. Os registros da administração pública, sejam financeiros, patrimoniais ou de pessoal, encontram-se digitalizados e armazenados em complexos sistemas de informática.

Neste contexto, o estudo teve como objetivo analisar o reconhecimento no trabalho de informática dos terceirizados e concursados de uma instituição pública. Para tanto, apresentamse, em seguida, os fundamentos teóricos que dão sustentação a estes objetivos.

\section{A Psicodinâmica do Reconhecimento}

Para a Psicodinâmica do Trabalho o reconhecimento funciona dentro do coletivo. Dejours (2011c) esclarece que o reconhecimento passa por julgamentos específicos, segundo uma dinâmica inserida na abordagem da psicodinâmica do trabalho: o julgamento de utilidade e o julgamento de beleza. O primeiro diz respeito à utilidade da contribuição técnica, social e econômica do sujeito e é proferido pela hierarquia, subordinados ou clientes (um juízo vertical).

$\mathrm{O}$ segundo, mais severo, diz respeito à qualidade, singularidade e originalidade de uma tarefa e é proferido pelos pares, por aqueles que conhecem bem as regras de ofício e o estado da arte (um juízo horizontal). No julgamento de beleza, os membros da 'comunidade de pertença' é que avaliam e julgam o trabalho. Porém, às vezes, o trabalhador não reconhece a contribuição de seu colega (e a sua própria), deixando de prestar o julgamento de beleza por não ter a consciência inteligível das contribuições.

\subsection{Reconhecimento e Sentido do Trabalho}

O trabalho é o espaço para o sujeito agir e determinar o sentido da sua atividade, mesmo com as privações inerentes à organização do trabalho. Dependendo de como o reconhecimento é empregado, o trabalhador é levado a uma reapropriação do sentido do trabalho e pode se autorealizar. Dejours (1992, p. 158) afirma que "os trabalhadores não têm sabido utilizar-se do trabalho que fazem como 'ressonância simbólica' na cena da angústia e do desejo" no lidar diário nas instituições e empresas. E continua dizendo que o trabalhador deveria "estudar os obstáculos que o trabalho coloca para essa 'ressonância metafórica'; por isso, o reconhecimento é um elemento de poder estruturador ou desestruturador do trabalho em relação à sua economia 
psíquica". A ressonância metafórica ocorre "quando há uma compatibilização entre as representações simbólicas do sujeito, seus investimentos e sua realidade de trabalho" (MENDES, 1995, p.), ou seja, os desejos e o empenho na tarefa por parte do trabalhador estão em consonância com o trabalho realizado.

Quando as pressões do trabalho não exercem apenas efeitos deletérios, a ação utilizada para subverter tal situação recebe o nome de "reapropriação". Para Dejours (1999a) trata-se de um processo pelo qual o sujeito não fica passivo diante das contradições do trabalho e cria formas para utilizar o trabalho para sua autorealização. $O$ trabalhador não se sujeita ou entra em servidão voluntária (MENDES, 2010).

Sobre o reconhecimento no trabalho, especificamente, são diversas as abordagens científicas em searas particulares. Entre eles destacam-se os estudos de Traesel e Merlo (2009) intitulado "A psicodinâmica do reconhecimento no trabalho de enfermagem". Nessa pesquisa utilizou-se como método entrevistas coletivas com 10 enfermeiros, acrescidas de conversas informais. $\mathrm{O}$ resultado mostrou que o reconhecimento mais importante provém dos pacientes (não da chefia ou dos colegas), e que há por parte dos enfermeiros um conflito por não conseguirem atender bem seus pacientes devido à sobrecarga de trabalho.

Destaca-se também o trabalho de Costa e Merlo (2010) sob o título "Reconhecimento e vida dos guardas municipais: clínica do trabalho na atividade de segurança pública”. Com base na metodologia da Clínica do Trabalho proposta por Christophe Dejours, em 2007, foram feitas entrevistas coletivas; a pesquisa foi dividida em quatro etapas: a demanda, a pré-pesquisa, a pesquisa (propriamente dita) e a validação. Foram entrevistados 10 guardas municipais e o resultado revelou que estes profissionais criam possibilidades de reconhecimento a partir do valor proferido pela população e pelos colegas e que investem na manutenção e reforço da hierarquia, como é comum no meio militar.

Registra-se, ainda, a pesquisa de Lima (2011), que demonstrou que o trabalho do cuidador é uma atividade que se constrói na relação com o outro, e exige forte mobilização subjetiva e contínua necessidade de inventividade. Apontou-se a organização do trabalho estudada como um local marcado pela precarização, o que dificulta o reconhecimento. Há um sentimento de impotência relatado e o medo frente a essas condições de precariedade. Além disso, trata-se de um grupo que se queixa da falta de voz no trabalho. Constatou-se que a falta de reconhecimento é o maior motivo para o sofrimento e o mesmo reconhecimento (junto com o fortalecimento do coletivo de trabalho) foi apontado como o caminho para encontrar prazer na atividade laboral. 


\section{Método}

A pesquisa se utilizou da abordagem da Psicodinâmica do Trabalho proposta por Dejours (1992) com as etapas: pré-pesquisa, pesquisa propriamente dita e restituição. Este método prevê a realização de sessões coletivas com grupos de trabalhadores submetidos à mesma organização do trabalho.

A organização do trabalho selecionada para a pesquisa e coleta de dados foi a Câmara dos Deputados, órgão integrante do Poder Legislativo na esfera federal. Mais especificamente o Centro de Informática dessa instituição, um departamento com aproximadamente 20 anos de existência, detentora de um histórico positivo de evolução tecnológica e com uma administração com hierarquia piramidal, como se vê em toda a instituição. É um dos órgãos com grande demanda de trabalho e é um dos departamentos com mais pessoas na situação de contrato terceirizado.

A pesquisa qualitativa é, inevitavelmente, influenciada pela subjetividade do pesquisador, sua bagagem, seu olhar. As verbalizações proferidas durante o contato interpessoal no momento das entrevistas definirão, com base na teoria, a interpretação dos dados, considerando o engajamento do pesquisador, e daqueles que o auxiliaram - o coletivo de controle.

Dejours (2001, p. 146), ao abordar a questão da interpretação esclarece:

Seria ilusório querer objetivar o sofrimento e o prazer, visto serem dados essencialmente subjetivos. Esses dados passam, tanto em suas descrições como na percepção, na detecção e na formulação pela subjetividade do pesquisador. [...] O objetivo é dar forma ao que, para o pesquisador, em seu contato com os trabalhadores, parece surpreendente, espantoso, incompreensível, doloroso, angustiante, agressivo [...] esta posição torna possível a abertura do 'discurso' sobre o sofrimento e sobre o prazer, discurso passível de escuta e de interpretação. Os elementos postos de forma clara permitem ao pesquisador a realização desse trabalho de formulação, verbalização, expressão.

Para Dejours (2011b) a palavra age mais como meio de fazer chegar à inteligibilidade, o que não é ainda consciente. A linguagem verbal tem a propriedade de ser um meio vigoroso de pensar, ou ainda, "falar e ser ouvido parece ser o modo mais poderoso de pensar e, portanto, de refletir sobre a própria experiência, desde que se esteja comprometido em uma relação dialógica, intersubjetiva, na qual se acredita que o outro esteja de fato tentando compreender" (DEJOURS, 1999a, p. 176 ).

Para Dejours (2011b), o movimento de fala e escuta, de explicação daquilo que se passa é bastante fecundo, pois os trabalhadores passam a formular coisas que nem eles próprios tinham como claras, até que se expressam de forma discursiva a uma pessoa que traz um olhar externo e isento, nem por isso neutro, em virtude da sua subjetividade que está sempre associada às suas interpretações. O mesmo autor (DEJOURS, 1992, p. 145) lembra: "a subjetividade do pesquisador encontra-se diretamente envolvida na técnica da pesquisa". 
A fala, no entanto, pode não dar nome a tudo que se passa com os sujeitos na organização do trabalho, camuflando situações e incoerências. Por isso, aquilo que é silenciado, muitas vezes deve ser objeto de atenção nesse método. Ainda assim, no decorrer das entrevistas, desvelaram-se verbalizações repletas de denúncia, sofrimento, estratégias defensivas e frustrações cuja ênfase pareceu ser o desejo pelo reconhecimento.

\subsection{Pré-pesquisa}

Motivado pela observação da área de informática da Câmara dos Deputados, o pesquisador foi afetado pela situação de conviverem, no dia a dia, trabalhadores terceirizados e concursados com diferenças contratuais gritantes, e se dispôs a investigar como se dá a psicodinâmica do reconhecimento, bem como os aspectos dessa organização do trabalho e as vivências de prazer e sofrimento dessas categorias e, ainda, como a instituição lida com as contradições e ambiguidades da terceirização no setor público. O pesquisador encontra-se na situação de usuário e cliente interno dos serviços prestados pela área de informática desse órgão.

Após contato com os participantes, houve uma descrição da pesquisa, seus objetivos, método e periodicidade dos encontros. Foi reservado espaço no local de trabalho, nas sextasfeiras à tarde. A pesquisa foi realizada no segundo semestre de 2011. Solicitou-se a assinatura do Termo de Consentimento Livre e Esclarecido, bem como autorização para gravação e posterior utilização.

A pesquisa contou com onze servidores concursados e sete funcionários terceirizados. A média de idade dos concursados era de 41,12 anos e dos terceirizados de 34,65 anos. E o tempo de serviço atuando no Centro de Informática da Câmara dos Deputados é de 5,1 e 7,5 anos respectivamente.

$\mathrm{Na}$ primeira entrevista com os concursados compareceram quatro homens e uma mulher; na segunda foram cinco homens e uma mulher; e na terceira quatro homens e uma mulher. Nas entrevistas com os terceirizados a participação se deu com cinco homens no primeiro encontro; quatro homens no segundo; e seis homens no terceiro.

\subsection{Pesquisa Propriamente Dita}

Foram realizadas três sessões de $2 \mathrm{~h}$ com cada categoria (entrevistas semiestruturadas), espaçadas por período de uma semana. Esse intervalo permite que os participantes elaborem aquilo que está sendo vivenciado e compartilhem seus sentimentos em relação ao que está sendo abordado.

As perguntas fundamentais para iniciar o discurso dos participantes foram: (1) Falemme sobre seu trabalho e como se sentem nele. (2) Quais as dificuldades encontradas no trabalho? (3) O que significa ser um concursado/terceirizados da área TI nesta instituição? (5) Vocês são valorizados/reconhecidos? 
A questão fundamental da pesquisa era saber se o trabalho era reconhecido, apesar das diferenças previamente observadas entre os servidores concursados e os funcionários terceirizados. Os dados coletados na pesquisa a partir das entrevistas coletivas apontaram uma fragilidade na identidade dos participantes e, sobretudo, no sentido do trabalho. Esses dados têm ligação direta com a literatura da Psicodinâmica do Trabalho no que diz respeito ao tema reconhecimento, conforme nos fala Sigaut (1990 apud DEJOURS, 2011a, p. 307): “sem o reconhecimento, não pode haver sentido, nem prazer (...) sem o reconhecimento do outro, a economia do sofrimento é destituída de sentido".

Dejours (1999a, p. 32), reforça esse raciocínio, lembrando que "o significado do sofrimento depende da psicodinâmica do reconhecimento. Se o sofrimento é reconhecido a pessoa pode repatriá-lo para o registro da construção de sua identidade”. E Segundo Dejours (1999b, p. 16-17) "para muitos o trabalho representa uma segunda chance de obter ou consolidar a identidade. (...) na falta de uma identidade bem estruturada, na qual no sintamos bem, na falta de autoestima, nós a buscamos no olhar do outro. O trabalho intervém, constituindo-se numa chance de obter o olhar do outro." Gernet (2010) também menciona uma ligação entre identidade e técnica podendo ser notadamente verificada com o reconhecimento.

\subsection{Restituição}

No início da segunda e terceira sessões houve uma devolutiva com a leitura da síntese do que havia sido falado no(s) encontro(s) anterior(es), bem como a compreensão desse conteúdo, realizando-se, assim, a validação dos dados. Estando todos de acordo, seguia-se com a nova etapa da entrevista. No final, foi realizada a síntese de todo material e aprovado pelos participantes, sempre com a oportunidade de se questionar ou alterar o que havia sido entendido.

\section{Resultados e Discussão}

A partir da fala dos participantes concursados, pode-se verificar uma organização do trabalho pautada em regras rígidas, conforme as falas: "a gente vê estratificações aqui dentro da instituição. São muito claras."; "o modelo de registro de presença é um modo de controle que reflete a gestão obsoleta da instituição...”.

Para se desenvolver um sistema é necessário contar com uma equipe, ou seja, ainda que haja momentos de isolamento para se chegar à lógica de um código de programação, a cooperação existe. Porém, é estritamente profissional, não avançando para o campo pessoalafetivo: "Não temos amigos, mas no trabalho existe cooperação"; "a gestão é autoritária". Desta forma, infere-se que não há espaço para os desejos subjetivos dos trabalhadores.

Dejours (1999a) fala que para se conseguir autorrealização e reconhecimento no trabalho, é necessário desencadear um processo de 'reapropriação'. Trata-se de um processo onde se utiliza uma estratégia para suportar as pressões e adversidades do trabalho, como uma 
resistência às patologias. A reapropriação, tal qual o próprio reconhecimento, age na construção da identidade e na saúde mental. Não se percebe nenhuma mobilização por parte dos concursados para promoverem esse processo. A qualidade dos relacionamentos dos concursados impede o alcance do reconhecimento como utilidade. (DEJOURS, 2011c).

Para os participantes terceirizados, as condições de trabalho são boas, mas quando comparadas as dos servidores, consegue-se apontar precariedades, em especial, no que diz respeito ao tamanho, conservação e localização de algumas salas; a fala sarcástica de um diretor denuncia: "isso aqui parece um poleiro de galinha".

Já os terceirizados apontaram uma organização do trabalho que distribui tarefas sem respeitar os cargos e respetivas atribuições: "há coisas que fazemos, mas não é atribuição nossa".

O contrato de trabalho é fragilizado; o salário bastante inferior, em uma organização que não mantém nenhum vínculo afetivo, consistente e duradouro com esta categoria que é vista como mão de obra "descartável": "eles jogam na nossa cara que podemos sair a qualquer momento. Não precisavam lembrar isso toda hora, a gente sabe. Ninguém gosta de ser sentir descartável";

Há sobrecarga de trabalho em um contexto onde são submetidos às mesmas normas rígidas, aos mesmos ritmos e horários. Embora executem seu trabalho ao lado dos concursados, há situações de precariedade mais acentuada apontadas por esses participantes, pois quando é necessário escolher qual categoria sofrerá privações, não há dúvida, segundo eles, que serão os terceirizados.

As relações socioprofissionais dos terceirizados foram pontuadas como boas e se estendem para fora da organização: "saímos juntos, às vezes". A gestão é autoritária e com ausência de sensibilidade (falta de consideração) à condição desfavorável do contrato de trabalho a que estão submetidos: "então já vem cobrança novamente e se não fizer do jeito deles..."; "esse tratamento causa um certo desmerecimento com o nosso trabalho".

No ambiente de trabalho dessa categoria, na maioria das vezes, a comunicação e cooperação ocorrem de forma harmônica e solidária: "A gente ajuda um ao outro, no atendimento". Gernet (2010) diz que é por meio da cooperação que se formulam os julgamentos menos contraditórios para se chegar ao reconhecimento, e Dejours (2011a, p. 91) aprofunda dizendo que "a dinâmica do reconhecimento no trabalho sugere que a cooperação é indissociável da economia da identidade e da saúde mental”.

Para Dejours (2011a, p. 82) a cooperação só se torna efetiva se os trabalhadores demonstrarem esse desejo de cooperar. Segundo o autor, nossa capacidade de resistir ou ficar doente está intimamente ligada à qualidade das relações de trabalho. E acrescenta: "a saúde de uma pessoa depende muito de seus colegas, isto é, das relações interindividuais". (DEJOURS, 1999a, p. 98). 
Registrou-se que os terceirizados sentem-se reconhecidos pelos usuários, conforme fala de um terceirizado: "alguns nos escolhem para atendê-los, porque são bem atendidos e nos conhecem pessoalmente". O lado do reconhecimento dos terceirizados pela contribuição (pelo julgamento de utilidade proferido pelos clientes-usuário), parece ser a razão para continuarem a trabalhar, ressignificando suas vivências de sofrimento.

Em relação ao reconhecimento como instrumento para se conseguir ressignificar o sentido do trabalho e acessar a trilha do prazer, foi apontado por Lima (2011) que o caminho para o sentido no trabalho é o fortalecimento do coletivo de trabalho.

\subsection{Discurso Narcísico}

Segundo o Dicionário "Vocabulário da Psicanálise de Laplanche e Pontalis" (2010, p. 287), o conceito de "narcisismo" foi utilizado por Freud pela primeira vez em 1910 referindo-se ao próprio corpo do objeto de amor, apoiado em princípios e conceitos psicanalíticos de "ego", "libido" e "objetos". |Contudo, sabe-se que o lexema é uma menção ao personagem Narciso, da mitologia grega, que se apaixonou por si mesmo ao ver sua imagem projetada nas águas.

Neste trabalho, porém, o conceito de "narcisismo" é utilizado no sentido de alguém que dá uma atenção excessiva a si mesmo. O Dicionário Aurélio (2004,) - oferecendo um conceito que vai mais ao encontro do senso comum - diz que "narcisismo" é "amor excessivo a si mesmo".

Os concursados têm o desejo de ser uma espécie de "elite" da instituição. A seguir, algumas falas que mostram esse desejo: "A gente quer virar uma supercategoria, mas o que estamos fazendo para isso? Será que estamos preparados?"; "Temos problemas complexos que a gente tem que destrinchar e os usuários têm superanseios"; "A informática deveria ser vista como estratégica"; "As pessoas colocam as esperanças delas em cima da gente..."; "As pessoas não têm conhecimento da nossa atividade e da dificuldade que é fazer o que nós fazemos".

Os estudos de Uchida (1996), bem como de Mansano e Malacrida (2011) apontaram características narcisistas ligadas aos profissionais de informática e associadas a importância e complexidade que esses profissionais dão às suas tarefas. Para ilustrar esse resultado, toma-se a pesquisa de Uchida (1996), que foi realizada com bancários da área de informática. Esses percebiam que os softwares por eles produzidos eram altamente complexos e com funcionamento praticamente livre de falhas. Os clientes dependiam totalmente dos programas desenvolvidos por eles e isso causava uma sensação de onipotência. Por outro lado, notou-se nesses profissionais uma autocobrança que os levava ao sofrimento ao se perceberem como pessoas sujeitas a falhas (pessoas inacabadas). Os analistas do setor bancário pesquisado apresentam semelhanças com os concursados desta pesquisa.

Dejours (1992, p. 49) alerta que a frustração narcísica precede a falta de significação no trabalho. Tentando achar sentido nas suas tarefas, um concursado verbaliza: "parece que o que 
eu faço se resume a um pedaço de papel e ninguém vai ver ou cumprir... por isso as frustrações perpassam todas as dimensões do trabalho e você acaba arrumando um jeitinho de driblar, porque senão...”. É a evidência de um trabalho não reconhecido, invisível e sem ressonância simbólica.

\subsection{Sentido no Trabalho}

Segundo Gaulejac (2007), quando o sentido prescrito não corresponde ao sentido que cada trabalhador dá, este vive uma incoerência que, longe de mobilizá-lo, leva-o a se desestimular com sua tarefa.

A fala de um concursado elucida essa situação: "Eu preciso vislumbrar alguma coisa para me motivar. Eu preciso ver o trabalho que eu vou fazer, que fruto aquilo vai dar. Se o trabalho for empilhar tijolo e pôr cimento... isso aí é um trabalho que é braçal, tá sem sentido. Igual aquele filme do Charles Chaplin, "Tempos Modernos", que fica apertando parafuso ali igual a um robô. Agora se fala, vamos construir um hospital. Vai beneficiar doentes, crianças, e tal... já é outra perspectiva, né? Você não está vendo aquilo que você tá fazendo ali no momento, você tá vendo algo maior".

A comparação com um trabalho braçal e sem ressonância simbólica demonstra a falta de reconhecimento e, ao mesmo tempo, ao se falar de um trabalho com perspectiva, um trabalho nobre (salvar vidas), mostra o desejo de ser reconhecido com a importância de alguém que usa seus conhecimentos por uma causa maior e que, portanto, deveria ser notado. Nesta pesquisa, essa verbalização representou toda uma categoria (insatisfeita e ressentida) em busca de um reconhecimento que não chega.

As expressões que mais chamaram a atenção e foram nomeadas pelos concursados, mostrando seu estado de insatisfação diante do que eles apresentaram como injustiça, desprezo e invisibilidade, foram: "como me sinto? Me sinto um abnegado e comprometido, apesar de preterido e desprezado"; "Eu me sinto confundido com o pessoal de atendimento e não quero isso"; - "Eu me sinto como um zumbi!"

A expressão "zumbi” é emblemática. É a reação de quem está desacreditado em tudo, depois de muito tentar ser notado, sem resultado. A renovação da mobilização subjetiva está fracassando. É a expressão daquele que resolveu ficar na instituição como um morto-vivo; uma pessoa sem expressão (sem voz), sem racionalidade (referindo-se a opiniões e a uma capacidade intelectual desprezada), como alguém que só aparece num horário em que não é visto; ou ainda, que é discriminado.

O filósofo australiano David Chalmers (1990, p. 1), cunhou o conceito de zumbi filosófico, "usado na filosofia da mente, campo de pesquisa que examina a associação entre pensamento consciente e o mundo físico". Para Chalmes (1990), zumbi filosófico é uma pessoa que não possui consciência plena, mas tem a biologia ou o comportamento de um ser humano 
normal, figura bastante apropriada no presente estudo, pois essa marcante afirmação está relacionada à falta de reconhecimento e à busca, sem êxito, dessa recognição e da própria identidade da categoria.

Nas verbalizações dos concursados, notou-se o desejo de serem percebidos como imprescindíveis, visto possuírem um conhecimento insólito aos demais na organização. Nas verbalizações dos concursados, notou-se o desejo de serem percebidos como imprescindíveis, visto possuírem um conhecimento insólito aos demais na organização. Os concursados se vangloriam do seu conhecimento, afirmando, com tom narcisista, que apenas eles podem ajudar os usuários, inclusive a fazê-los ver o que precisam, desembaralhando seus pensamentos confusos (Cf. UCHIDA, 1996). Do ponto de vista psicanalítico, o narcisismo dos concursados transparece em seu discurso: "as pessoas colocam as esperanças deles em cima da gente. "; "nem eles sabem o que querem e precisam de nós para resolverem seus problemas"; para nós pode ser simples, mas, na verdade, há muitas coisas complexas por trás.”.

Uma metáfora bastante utilizada pelos concursados foi a analogia com a lâmpada que ilumina um ambiente. A luz elétrica nem é mais percebida de tão comum e, por isso, as pessoas não param para pensar no trabalho que deu para que aquela iluminação chegasse até o referido ambiente. Para os concursados, o mesmo acontece com o trabalho que desenvolvem.

Os concursados alimentam uma expectativa de reconhecimento que, de tão grande, não pode ser atendida pela instituição. Essa expectação começa a ser alimentada antes da entrada na instituição, ainda na época dos estudos para o concurso. De fato, há todo um fetiche que se atribui à questão da aprovação e entrada na instituição.

Neste caso, o dano que a corrida pelo reconhecimento traz é que a disputa passa a ser individual, e não mais da categoria, enfraquecendo o coletivo. Segundo um dos participantes, "tudo passa a se resumir em sair da área de TI para ganhar mais". Como isso não é tão simples, uma vez que nem todos conseguirão sair ou receber as funções comissionadas necessárias, o desânimo toma conta dos concursados. O que parece estar patente para os concursados está apenas no seu imaginário e não é visto da mesma maneira pelos outros setores e pela alta administração da instituição. Com isso, estariam os servidores concursados sendo privados de se adaptarem ou se mobilizarem? Ou não estão sabendo como se organizar, valendo-se da força do grupo e do seu elevado conhecimento técnico?

A luta pelo reconhecimento parece fazer com que os concursados ajam empenhando-se para serem notados individualmente, já que a categoria, segundo entendem, está oculta aos olhos da administração. Gaulejac (2007, p. 26), fala sobre "a luta dos lugares", referindo-se à competição imposta pelo sistema gerencialista, nutrido pelo capitalismo.

Uma das tentativas para serem vistos ou buscarem mais funções para a área é o aumento do serviço, aceitando toda e qualquer demanda. A busca por mais serviços para ser uma categoria perceptível trouxe uma cilada que é verificada nas queixas de ambas as categorias 
pesquisadas a respeito da sobrecarga, reforçando o comentário de um dos participantes de que os diretores não sabem dizer "não" e acumulam serviços que sobrecarregam sua equipe. Enquanto esse quadro não é visto pela administração, a corrida pelo reconhecimento deixa os concursados obliterados da sua razão esquecendo-se do coletivo.

Presos à argumentação de que não podem sair da área de TI, os concursados não conseguem atentar-se que, como profissionais altamente qualificados, são praticamente insubstituíveis, uma vez que não há outros profissionais capacitados, como eles, para desenvolver sistemas de informática complexos, para proteger as informações ou garantir a segurança da rede de computadores, por exemplo. O próprio discurso de que os usuários dependem deles e mal sabem identificar seus próprios problemas, dito pelos concursados, não é utilizado em favor da sua causa.

Enfim, os concursados são importantes para a instituição, mas não conseguem se mobilizar para mostrar isso como categoria; para dar visibilidade às suas tarefas. $\mathrm{O}$ desejo de reconhecimento de ambas as categorias (terceirizados e concursados, com ênfase para este último) é legítimo, mas a mobilização subjetiva para isso se mostrou insuficiente. Os terceirizados, em especial, estão limitados para a mobilização subjetiva pela situação contratual a que estão vinculados. O enfrentamento contra as perversidades da organização do trabalho fica comprometido, senão inexistente. No caso dos concursados, a mobilização subjetiva poderia ser um instrumento para alcançarem a visibilidade que desejam. Mas se, por um lado, o desejo de reconhecimento dos concursados é legítimo, por outro o tomo dessa expectativa alcança certo nível impossível de ser concedido pela instituição.

A urgência do atendimento à necessidade de reconhecimento dos concursados faz com que não percebam a si mesmos e desloquem suas ações e inteligência, que deveriam ser coletivas, para questões individuais e ligadas meramente à materialidade, como resultado de uma frustração.

Ao serem perguntados sobre o que mais lhe incomoda, as respostas dos concursados foram: "menosprezo"; "sobrecarga"; "desmotivação da categoria"; "tratamento desigual", uma visão que não corresponde àquilo que tinham ao entrarem no órgão. Como a instituição que trabalham oferece conforto, status e salários acima da média em relação a outros órgãos públicos, é uma declaração que surpreende.

Era de se esperar que tais palavras aparecessem de forma natural nas respostas dos terceirizados, sobretudo as palavras "menosprezo" e "tratamento desigual", visto que os próprios concursados tratam os terceirizados com menosprezo e desigualdade, conforme relatos da pesquisa. Isso não faz com que a resposta dos concursados possa ser vista como ilegítima, mas mostra a distância da realidade dos dois grupos pesquisados e a decisão acertada de entrevistá-los separadamente. Revela que seus interesses e seus mundos são distintos demais para possíveis comentários que acusem os concursados de reclamarem "de barriga cheia", pois 
na realidade deles, em relação às suas expectativas e capacidades, se sentem menosprezados e apartados do sistema. Com base em exemplos e dados, essas declarações são justificadas, mas criou-se um imaginário excessivo que tem causado dano ao estado emocional dessa categoria.

A autoimagem que os concursados carregam é a de que seu trabalho é importante, mas invisível, sem reconhecimento. Está aí a base do que deve ser trabalhado nesse coletivo: o reconhecimento. Hoje, o que se verifica é um trabalho sem ressonância simbólica, desinteressante, sem sentido. A área exige uma manutenção intelectual; a grande maioria está frustrada, por não serem elogiados ou não conseguirem status dentro da organização, seja em forma de gratificações simbólicas e materiais. Apesar da verbalização preconceituosa e discriminatória, assumem que não estudaram/estudam tanto para serem confundidos com "terceirizados" ou "simples funcionários". A expectativa que alimentaram antes de entrarem no serviço público foi sendo frustrada a cada dia, ao se depararem com o real do trabalho e com o trabalho invisível que, para eles, não faz sentido.

Para os concursados seu trabalho deveria ter mais visibilidade, visto que a tecnologia é apoio para todos os outros setores. Na visão deles, sem tecnologia nenhuma instituição funciona e as pessoas não conhecem (e por isso não reconhecem) o quão complexo é manter um serviço de informática em funcionamento regular e seguro. A expectativa não correspondida, diante da invisibilidade de suas contribuições, gera um grupo com uma identidade comprometida134.

O movimento dos concursados expresso na tentativa de sair do setor de informática, frustrado pelas normas internas, desmantela $o$ coletivo $e$ instala a competição. $O$ reconhecimento proveniente do julgamento de utilidade que já não existia, agora atinge o julgamento de estética, uma vez que os pares não têm condições de se reconhecerem por causa do pano de fundo da rivalidade velada.

Moraes e Vasconcelos (2011, p. 130) declaram que:

A noção de cooperação requer a existência de uma relação de confiança entre os colegas de trabalho, os subordinados e a chefia, mas alerta também para o fato de que nos dias atuais as relações de trabalho estão cada vez mais pautadas na competição e no individualismo, fatores que podem certamente dificultar a dinâmica do reconhecimento.

Mendes (2008b) reforça esse raciocínio dizendo que a confiança nos espaços de convivência é fundada sobre a consciência de uma comunidade pautada em valores que permita se alternar intimidade e visibilidade.

Além da indiferença da administração, apontada nos discursos dos concursados, há um elemento fundamental que corrobora para o não-reconhecimento por parte dos seus clientes: o tempo para a conclusão das tarefas. A análise de sistemas e o desenvolvimento de programas ficam a cargo dos concursados. Isso implica um investimento de, em média, dois anos até a finalização dos produtos demandados. Com o passar do tempo, a realidade dos setores demandantes muda e o sistema que foi concebido pode tornar-se obsoleto antes mesmo de entrar 
em produção, ou seja, em uso. De forma geral, não há vínculo entre o programador e o cliente. No processo de trabalho não está previsto o contato com o cliente de forma a criar laços. Assim, os analistas ficam afastados desse contato com o trabalho do usuário, configurando um descompasso nessa relação. Durante o desenvolvimento de um sistema, não raro, ambos (demandante e desenvolvedor) mudam de setor e o pedido se perde ao longo do tempo. Desse modo, o trabalho perde o sentido, não se vislumbrando, de forma palpável, sua utilidade e, por conseguinte, não podendo haver julgamento de utilidade por parte do cliente.

Já no trabalho dos terceirizados testemunha-se o contrário. Esse grupo é responsável pelo atendimento in loco aos clientes que se deparam com problemas em seus computadores no dia a dia. Isso faz com que eles tenham contato diferenciado com as pessoas e desenvolvam vínculo com eles. O retorno do seu trabalho é imediato, com manifestações de reconhecimento no sentido de utilidade e, desta forma, promovendo sentido ao trabalho. A visibilidade e a importância de suas tarefas são evidentes, ainda que possam ser menos complexas que o desenvolvimento de um sistema.

Os terceirizados, por outro lado, afirmam que para cumprir suas tarefas é necessário muito conhecimento técnico, motivo de orgulho entre eles. Como não estão competindo entre si, há um clima de solidariedade onde um ajuda ao outro para darem conta das demandas que são pressionadas pelo tempo e pelas normas internas.

A consequência dessa conjuntura é um grupo de terceirizados com forte identidade, apesar do sentimento de discriminação e menor status. Um grupo com mobilização subjetiva coletiva que consegue ressignificar seu sofrimento e transformá-lo em prazer, ressaltando o sentido do seu trabalho e se utilizando dessas estratégias para atenuar a insegurança do próprio emprego que pode resultar em perdas e comprometimentos sócio-econômicos. Diante das adversidades, esses trabalhadores têm encontrado sentido no que fazem. Como disse Dejours (1992, p. 158), isso ocorre quando o sujeito consegue "utilizar-se do seu trabalho como 'ressonância metafórica' na cena da angústia e do desejo".

Isto é, se uma organização do trabalho é indiferente à sua situação laboral, à história individual/coletiva e ao investimento físico ${ }^{1}$, cognitivo e afetivo dos trabalhadores, as soluções para a manutenção do prazer no trabalho devem surgir do coletivo de trabalhadores. Quando o sentimento de grupo está presente, essa mobilização, além de afetar o individual, desdobra-se poderosamente para o coletivo. Para Moraes e Vasconcelos (2011, p. 130) "a possibilidade de atribuir um sentido ou um significado para a atividade realizada inscreve-se precisamente na dinâmica do reconhecimento por se constituir como uma via legítima de acesso à vivência de

\footnotetext{
${ }^{1} \mathrm{O}$ investimento físico é aquele do corpo físico que é - ou foi - marcado por uma história atravessada pela cultura e experiências adquiridas.
} 
prazer no trabalho". Mendes (2008a) ressaltar que é por intermédio do reconhecimento que a atividade do sujeito-trabalhador adquire significado simbólico.

Os terceirizados que, aparentemente, teriam motivos para apresentarem falta de reconhecimento, superam, em termos comparativos, os concursados nesse quesito. E quanto aos concursados, embora sua competência seja indiscutível e seja difícil negar que a tecnologia permeia a vida de todos, não se pode concluir que sua importância esteja na estreita dependência de pessoas de uma "superclasse", merecedora de um reconhecimento acima daquilo que as pessoas e as instituições possam dar.

\section{Conclusão}

Esta pesquisa demonstrou que a importância da tecnologia não é suficiente para dar sentido ao trabalho dos profissionais da área de Tecnologia da Informação. A dinâmica do reconhecimento apareceu de forma mais nítida quando se analisou separadamente as duas categorias em voga, verificando-se duas realidades distintas em um mesmo setor de trabalho. Como as entrevistas coletivas foram conduzidas com dois grupos (concursados e terceirizados), a comparação das contradições entre o prescrito e o real e as diferenças nas vivências de prazer e sofrimento das categorias foi bem identificada e a análise ocorreu, dentro das limitações imanentes à fala e a qualquer metodologia, possibilitando compreender a organização do trabalho, as vivências de prazer e sofrimento e a dinâmica de reconhecimento das categorias em voga. Entende-se, pelo exposto, que a pesquisa atingiu seus objetivos. Os resultados sugerem que os concursados não alcançam reconhecimento, o que se dá com os terceirizados. Isso resulta em desdobramentos, tanto na construção, quanto na consolidação de suas identidades. Deve-se ressaltar que a lógica de contratação de trabalhos terceirizados deve ser revista à luz da legislação e da ética, sob pena de se perpetuar uma prática perversa do ponto de vista daqueles que são contratados sob a égide da 'terceirização'.

Em comparação aos concursados, os terceirizados mostraram-se mais capazes de garantir visibilidade ao seu trabalho, outorgando sentido nas tarefas do cotidiano e ressignificando seu sofrimento com ações simples e estratégicas defensivas mais eficazes, ainda que entre elas haja a racionalização, o conformismo e a justificação. Identifica-se também no trabalho dos terceirizados o juízo da beleza proferido pelos colegas.

Os resultados desta investigação a partir dos achados, da análise e interpretação correspondem a uma "fotografia", um momento da instituição, uma espécie de representação das categorias, vista a partir da subjetividade dos participantes. 


\section{Referências}

AGUIAR, Verônica Brito. Psicodinâmica da relação gestor-equipe: análise do prazersofrimento no trabalho em uma organização pública. $107 \mathrm{f}$. Dissertação (Mestrado em Psicologia Social, do Trabalho e das Organizações), Instituto de Psicologia, Universidade de Brasília, Brasília, 2013.

ANTUNES, Ricardo; SILVA Maria Aparecida S. (Org.). O avesso do trabalho. 2. ed. São Paulo: Expressão Popular, 2010.

ANTUNES, Ricardo. Adeus ao trabalho?: ensaios sobre as metamorfoses e a centralidade do mundo do trabalho. São Paulo: Cortez, 1995.

CARVALHO, Marília Amélia Lira. Pejotização e descaracterização do contrato de emprego: o caso dos médicos em Salvador. 153 f. Dissertação (Mestrado em Políticas Sociais e Cidadania), Universidade Católica de Salvador - UCSal, Bahia, 2010.

CHALMERS, David. O zumbi filosófico, 1990. Disponível em http://pt.wikipedia.org/wiki/Zumbi Acesso em 08 de março de 2012.

DAU, Denise Motta; RODRIGUES, Iram Jácome; CONCEIÇÃO, Jefferson José. (Org.). Terceirização no Brasil: do discurso da inovação à precarização do trabalho (atualização do debate e perspectivas). São Paulo: Annablume; CUT, 2009.

DEJOURS, Christophe. A loucura do trabalho. 5. ed. ampliada. São Paulo: Cortez - Oboré, 1992.

Conferências brasileiras: identidade, reconhecimento e transgressão no trabalho, São Paulo: Fundap, EAESP/FGV, 1999a.

Entrevista sobre psicodinâmica e psicopatologia do trabalho e psicossomática. Ágora: Estudos em Teoria Psicanalítica, Rio de Janeiro, v.4, n.2. p. 89-94. jul/dez. 2001.

. A violência invisível. Revista Caros Amigos, São Paulo, v. 1, n. 24. p. 1-6, maio 1999b.

Addendum: da psicopatologia à psicodinâmica do trabalho. In: LANCMAN, Selma; SZNELWAR, Laerte Idal (Org.). Título. 3. ed. Local: Ed. Paralelo 15 ,2011a. p. 57-124.

. Análise psicodinâmica das situações de trabalho e sociologia da linguagem. In: LANCMAN, Selma; SZNELWAR, Laerte Idal (Org.). Título. 3. ed. Local: Ed. Paralelo 15, 2011b. p. 287-340.

. Alienação e clínica do trabalho. In: LANCMAN, Selma; SZNELWAR, Laerte Idal (Org.). Título. 3. ed. Local: Ed., 2011c. p. 255-286.

FERREIRA, Angela da Silva. A psicodinâmica do trabalho de profissionais de odontologia do centro ambulatorial de um hospital universitário. $106 \mathrm{f}$. Dissertação (Mestrado em Psicologia Social, do Trabalho e das Organizações), Universidade de Brasília - UnB, Brasília, 2013.de mestrado em Psicologia Social, do Trabalho e das Organizações, 106 f. Universidade de Brasília - UnB. Brasília, 2013.

FONSECA, Paulo José Silva; MORAES, Rosângela Dutra. Líder sofre? Subjetividade e sofrimento no trabalho de líderes no pólo industrial de Manaus. Revista AMAzônicaUFAM, Manaus, ano 5, vol 9, n.2. p. 69-85. jul/dez. 2012.

FREITAS, Lêda Gonçalves. Saúde e processo de adoecimento no trabalho dos professores em ambiente virtual. $235 \mathrm{f}$. Tese (Doutorado em Psicologia), , Universidade de Brasília UnB, Brasília, 2006.

GARCIA, Wiulla Inácia. Análise Psicodinâmica do Trabalho no Tribunal de Justiça do Amazonas: Uma aplicação da Clínica do Trabalho e da Ação. 190 f. Dissertação (Mestrado em Processos Psicológicos e Saúde), Universidade Federal do Amazonas - UFAM. Manaus, 2011. 
GAULEJAC, Vicent. Gestão como doença social: ideologia, poder gerencialista e fragmentação social. Aparecida, SP: Ed. Idéias \& Letras, 2007.

GERNET, Isabelle. Psicodinâmica do reconhecimento. In: MENDES, Ana. Magnólia. (Org.). Psicodinâmica e clínica do trabalho: temas, interfaces e casos brasileiros. Curitiba: Juruá, 2010. p. 61-76.

LIMA, Suzana, Canez. C. Coletivo de trabalho e reconhecimento: uma análise psicodinâmica dos cuidadores sociais. $220 \mathrm{f}$. Tese (Doutorado em Psicologia Social, do Trabalho e das Organizações), Universidade de Brasília - UnB, Brasília, 2011.

MANSANO, Sônia Regina V; MALACRIDA, Samira. L. A relação homem-computador: um estudo sobre o sofrimento psíquico entre analistas de sistemas. Em Extensão, Uberlândia, v. 10, n. 1, p. 34-45, jan./jun.2011.

MARTINS, Soraya. Rodrigues. Tempo antes do adoecer: relações entre saúde e os processos psicodinâmicos do reconhecimento do trabalho. In: MENDES, A. M. (Org.). Trabalho e Saúde. Curitiba: Juruá, 2008. p. 69-88, mês ano.

MENDES, Ana Magnólia. Aspectos psicodinâmicos da relação homem-trabalho: as contribuições de C. Dejours. Psicologia Ciência e Profissão, Brasília, v. 15, n. 1-3, p. 34-38, mês 1995 .

. Prazer, reconhecimento e transformação do sofrimento no trabalho. In: Mendes, A.

M. (Org.). Trabalho e Saúde. Curitiba, Juruá, 2008a. p. 13-25.

. Violência no trabalho: perspectivas da psicodinâmica, da ergonomia e da sociologia clínica. In: Mendes, Ana. Magnólia. (Org.). Violência no trabalho. São Paulo: Mackenzie, 2010. p. 91-106.

MENDES, Ana. Magnólia; ARAÚJO, Luciane Kozics Reis. Clínica psicodinâmica do trabalho: práticas brasileiras. Brasília: Ex Libris, 2011.

MORAES, Rosangela. Dutra; VASCONCELOS, Ana Cláudia Leal. (Org.). Subjetividade e trabalho com automação: estudo no polo industrial de Manaus. Manaus: Edua, 2011.

NARCISISMO. In: Novo DICIONÁRIO Aurélio, versão 5.11. Edição Eletrônica autorizada à empresa Positivo Informática Ltda. Regis Ltda, 2004.

NARCISIMO. LAGACHE, Daniel. VOCABULÁRIO da Psicanálise Laplanche e Pontalis. Tradução Pedro Tamen. $4^{a}$ Ed. São Paulo: Martins Fontes, 2010.

ROSAS, Maria Letícia M.; CASTRO, Max. A. O reconhecimento no trabalho do polo industrial de Manaus. In: MORAES, Rosangela Dutra. et al. (Org.). Subjetividade e trabalho com automação: estudo do polo industrial de Manaus. Manaus: Edua, 2011. p. 125-134.

UCHIDA, Seiji. Temporalidade e subjetividade no trabalho informatizado. $323 \mathrm{f}$. Tese (Doutorado em Psicologia), Instituto de Psicologia - Universidade de São Paulo - USP, São Paulo, 1996.

Artigo recebido em: 18/06/2014

Artigo aceito para publicação em: 04/08/2014 